\section{La ética de la publicación médica: entre la academia, el estado y la industria}

\author{
Fernando Lolas ${ }^{1}$
}

La publicación médica cumple por lo menos dos propósitos: amplía la base de conocimientos en las disciplinas de la medicina y renueva estas disciplinas en sus principios y en sus métodos. Esto se logra mediante textos primarios, que comunican información en forma original y reproducible para los pares; secundarios, que agrupan y sintetizan la información disponible, y terciarios, que recogen en libros de texto lo que ha dejado de ser motivo de controversia. A esta lista de publicaciones se podría agregar la cuaternaria, constituida por literatura de divulgación escrita por los propios investigadores.

La tradicional visión de la publicación como un logro del investigador individual que labora en el medio académico y entrega sus conocimientos a cambio de prestigio entre sus pares y ascensos en su carrera debe ser modificada. Se encuentran cada vez con mayor frecuencia grupos de autores que se conciertan para realizar estudios multicéntricos, a menudo auspiciados y financiados por la industria. Por otra parte, las organizaciones de investigación por contrato (OIC), que median entre los patrocinadores financieros y los investigadores, reciben alrededor de $60 \%$ de los subsidios de investigación proporcionados por la industria farmacéutica.

Estos hechos, sumados al crecimiento notable del volumen de los ensayos controlados aleatorizados (randomized controlled trials), plantean desafíos éticos que se agregan a los tradicionales en la práctica de la publicación biomédica. Por de pronto, la calidad de los informes requiere aun mayor escrupulosidad desde el punto de vista técnico (1). Pero, además, la publicación de estos estudios tiene un impacto directo sobre los intereses económicos, tanto los de las empresas como los de los investigadores.

Junto con el contexto del descubrimiento y el contexto de la justificación, tradicionales aspectos del trabajo científico, es necesario ahondar en el "contexto de la publicación", sin el cual todo esfuerzo generador de conocimientos queda truncado (2). En otro sitio hemos elaborado la distinción entre la legalidad y legitimidad de la publicación médica. El primer concepto alude a la solvencia técnica y a la aceptación por los pares; el segundo se refiere al cumplimiento de los estándares éticos en la obtención y diseminación de información (3).

El primero de estos aspectos, lo que llamamos legalidad, ha sido responsabilidad tradicional de autores y editores. Aunque los patrocinadores financieros se interesan por la calidad de los estudios que apoyan, las consideraciones de orden ético, derivadas de la forma en que actualmente se financia y difunde la información, merecen una discusión especial. Numerosas publicaciones reflejan la importancia y pertinencia de tal discusión y son de singular interés en el contexto de las naciones de América Latina y el Caribe (4).

Un tema ampliamente debatido se relaciona con el llamado "sesgo de la publicación". Aunque no es privativo de la producción médica financiada por la industria, el hecho de que los resultados negativos sean generalmente omitidos y los positivos se informen de forma redundante es un punto de interés. Por una parte, puede entenderse que la industria no desee ver desprestigiados sus productos por publicaciones que indican su eventual inutilidad o su modesta eficacia. Por otra, los editores suelen ser renuentes a publicar resultados que no conducen a conclusiones firmes. El problema ético se plantea cuando del conjunto de las publicaciones se desea derivar pruebas empíricas de eficacia. Al no disponerse de la totalidad de la información sobre un determinado producto, las conclusiones - y por ende la práctica- pueden verse afectadas. La publicación de resultados que solamente repiten lo ya conocido afecta especialmente a los investigadores jóvenes o de instituciones poco acreditadas y obliga a reflexionar sobre el sentido del término "investigación médica" en ciertos contextos. En todo caso, si un resultado ha sido previamente publicado en forma diferente de una presentación preliminar, ello debe comunicarse en el nuevo texto.

La industria farmacéutica de frontera, aquella que invierte en el desarrollo y la investigación, suele tener rigurosos estándares éticos para la conducción de los estudios. No es infrecuente en países con reglamentaciones laxas o imprecisas que se tomen tales estándares por suficientes y que no se sometan a examen por parte de los comités locales de ética. Tal postura es inadecuada, toda vez que un principio esencial de la supervisión en materia de ética es que la lleve a cabo un cuerpo independiente de evaluadores que conozca 
el entorno concreto en que se realizará el estudio y que tenga en cuenta los factores culturales y sociales pertinentes.

Puede malentenderse el apoyo de la industria y suponerse que, siendo la patrocinadora, puede influir sobre la forma y profundidad de la presentación pública de los estudios. Si bien los fabricantes de un producto pueden solicitar que pase un tiempo razonable antes de que se publiquen estudios basados en él, la propiedad de la información y la oportunidad de difundirla públicamente deben ser materia de una discusión franca y abierta antes de iniciar el estudio. Esto no solamente es válido para los estudios patrocinados o financiados por la industria. También se aplica a quienes trabajan en institutos gubernamentales o en fundaciones que se reservan la propiedad intelectual de los productos de sus empleados.

En los países de América Latina y el Caribe el problema de la comunicación pública sobre materias científicas y médicas es tan importante como en otros lugares del mundo. Sigue siendo válido el principio de que no debe darse a la prensa material que no ha sido evaluado por editores o sometido al juicio de los pares (la llamada regla de Ingelfinger). Sin embargo, no es infrecuente escuchar el deseo de que avances importantes puedan ser divulgados en tiempos menores que los requeridos para el análisis científico, especialmente si pueden salvar vidas o reducir sufrimiento. $\mathrm{Al}$ respecto, cabe recalcar que la equidad en el acceso a la información nunca debe confundirse con propalar información insuficiente o parcial (5). En realidad, la frecuencia con que se producen hallazgos o noticias espectaculares es más bien baja y no se justifica éticamente crear expectativas desmesuradas en poblaciones vulnerables y crédulas.

La publicación en medios electrónicos (especialmente en Internet) es, para todos los fines, publicación equiparable a la que se realiza en papel y en libros. Son válidas para ella todas las consideraciones precedentes sobre calidad, responsabilidad y control ético. La relativa facilidad de acceso al medio, unida a la posibilidad de anonimato en materia de autoría, obligan a considerar cuidadosamente la confiabilidad y calidad de los sitios "web". Cuando ellos sean patrocinados por la industria este hecho debe ser expresamente indicado. El medio proporcionado por Internet, al permitir una amplia interacción entre autores y lectores, desdibuja el concepto mismo de autoría puesto que las réplicas y contrarréplicas pueden incorporarse al texto original sin indicación especial y a veces sin control editorial adecuado. Desde el punto de vista ético, sin embargo, los autores deben estar conscientes de que su condición de tales implica responsabilidad e independencia y que realizar estudios innecesarios, comunicar resultados inexactos o dudosos o defraudar en materia de autoría son transgresiones éticas que la comunidad científica se esfuerza en evitar.

En los últimos tiempos, el problema de la censura de la comunicación científica se presenta bajo una faz diferente de la relacionada con la industria y sus intereses comerciales. El bioterrorismo supone la amenaza de que individuos o grupos puedan obtener conocimientos por adelantado (por ejemplo, en microbiología) que podrían usarse con fines de agresión y exterminio. Aunque aquí intervienen consideraciones de seguridad nacional y regulaciones propias del estado bélico, los autores y editores tienen ante sí el importante desafío de ponderar los riesgos y beneficios de la comunicación médica y de encontrar el justo equilibrio entre la libertad de información y su restricción por precaución justificada.

Así, entre la academia, el estado y la industria se teje una red de intereses que la comunicación médica deberá considerar en sus futuros desarrollos. Como en otros ámbitos, también en este el papel de las organizaciones internacionales (la Organización Panamericana de la Salud, entre otras) será el de equilibrar, moderar y fomentar la creación y la aplicación del conocimiento con la neutralidad de un ente técnico.

\section{REFERENCIAS}

1. Moher D, Schulz KF, Altman DG, CONSORT Group. The CONSORT statement: revised recommendations for improving the quality of reports of parallel-group randomised trials. Lancet 2001;357:1191-1194.

2. Lolas F. Communication modes in research. En: Day SB, Lolas F, Kusinitz M. (editores) Biopsychosocial Health. New York: International Foundation for Biosocial Development and Human Health; 1980.

3. Lolas F. Ética de la publicación médica: legalidad y legitimidad. Acta Bioethica (Santiago) 2000;6:285-291.

4. Wager E, Field EA, Grossman L. Good publication practice for pharmaceutical companies. Curr Med Res Opin 2003;19:149-154.

5. Lolas F. Información, comunicación y equidad: dilemas en el ámbito sanitario. Rev Panam Salud Publica 2002:11;430-434. 